\title{
Discovery of an insertion sequence, IS116, from Streptomyces clavuligerus and its relatedness to other transposable elements from actinomycetes
}

\author{
Brenda K. Leskiw, ${ }^{1}{ }^{*} \dagger$ Moshe Mevarech, ${ }^{1} \ddagger$ Lorinda S. Barritt, ${ }^{1}$ Susan E. Jensen, ${ }^{1}$ \\ Duncan J. Henderson, ${ }^{2} \S$ David A. Hopwood, ${ }^{2}$ Celia J. Bruton ${ }^{2}$ and Keith F. Chater ${ }^{2}$ \\ ${ }^{1}$ Department of Microbiology, University of Alberta, Edmonton, Alberta, Canada T6G 2E9 \\ ${ }^{2}$ John Innes Institute, John Innes Centre for Plant Science Research, Colney Lane, Norwich NR4 7UH, UK
}

(Received 5 February 1990; revised 20 March 1990; accepted 2 April 1990)

\begin{abstract}
We have identified an insertion sequence, IS116, present in Streptomyces clavuligerus at one copy per genome. The element was discovered as a $1.4 \mathrm{~kb}$ insertion into the multicopy plasmid pIJ702 after propagation in $S$. clavuligerus. The nucleotide sequence of IS116 and the flanking sequences from PIJ702 have been determined. The junctions with pIJ702 show no target site duplication and there are no inverted repeats at the ends of the element. One putative coding open reading frame of 1197 bp was identified which would code for a protein product of 399 amino acids. This protein resembles deduced integrase/transposase proteins specified by three other transposable elements of actinomycetes: IS110 and the mini-circle from Streptomyces coelicolor A3(2), and - most particularly - IS900 of Mycobacterium paratuberculosis. Two regions that are relatively conserved among these gene products show features found in similar positions in many reverse transcriptases. IS116 and IS900 are also closely similar in their general organization and (apparently) in their insertion site specificity, whereas IS110 and the mini-circle are quite different in these features.
\end{abstract}

\section{Introduction}

Members of the genus Streptomyces are noted amongst bacteria for their high level of spontaneous genetic variability, which can affect many characters, including their two most notable properties: the production of secondary metabolites and their sporulation. In recent years, with the availability of an increasingly wide variety of molecular genetic techniques for use in Streptomyces, some of the basis for this genome flux is being revealed, with the description of deletion and amplification cycles in the chromosomal DNA of these organisms (reviewed by Hütter \& Eckhardt, 1988). Several mobile genetic elements, including insertion sequences and transposons, which might play a role in

† Present address: John Innes Institute, John Innes Centre for Plant Science Research, Colney Lane, Norwich, NR4 7UH, UK.

$\ddagger$ Present address: Department of Microbiology, George S. Wise Faculty of Life Sciences, Tel Aviv University, Tel Aviv, Israel.

$\S$ Present address: Fisons plc, Pharmaceutical Division, Bakewell Road, Loughborough LE11 ORH, UK.

Abbreviation: ORF, open reading frame.

The nucleotide sequence data reported in this paper have been submitted to GenBank (accession number M31716). genome flux in streptomycetes have also been described, most notably in Streptomyces coelicolor A3(2), which is genetically the most studied member of the genus (reviewed by Chater et al., 1988).

Among the few elements sequenced so far, relatedness to other known prokaryotic or eukaryotic sequences in the major protein databases has not been revealed. However, IS 110 (Chater et al., 1985; Bruton \& Chater, 1987 ) and the $2.6 \mathrm{~kb}$ mini-circle (Lydiate et al., 1986; Henderson $e t$ al., 1989) from $S$. coelicolor and the recently discovered IS 900 from Mycobacterium paratuberculosis (Green et al., 1989) have been found to form a 'family' of related elements based on similarity between amino acid sequences of their deduced gene products, despite the diversity of structure and host strains of these elements. The use of both ISI10 and the mini-circle sequences to probe the DNA of a series of taxonomically varied streptomycetes revealed related elements in a minority of strains (Chater et al., 1985; Lydiate et al., 1986), but no hybridization to $S$. clavuligerus DNA. However, as we report here, an element (IS116) containing a major open reading frame resembling those of $I S 110$, the mini-circle and, most particularly, IS 900 has now been isolated from $S$. clavuligerus. 


\section{Methods}

Bacterial strains, culture conditions, plasmid and phage vectors. Streptomyces clavuligerus NRRL 3585 and other Streptomyces cultures were maintained on sporulation medium as described previously (Jensen et al., 1982). For mutagenesis, S. clavuligerus spores were pregerminated for $5 \mathrm{~h}$ in seed medium [O'Sullivan et al., 1979, except that phytone (Difco) replaced soy flour and sucrose was omitted] and harvested by filtration $(0.45 \mu \mathrm{m}$ pore size, Millipore). For the preparation of protoplasts, $S$. clavuligerus was cultured as described by Bailey \& Winstanley (1986). Protoplasts of S. clavuligerus were prepared and the protoplasts were transformed and regenerated as described previously (Leskiw et al., 1988). For the preparation of genomic DNA, $S$. clavuligerus was cultivated as described by Jensen $e t$ al. (1986), and all other Streptomyces strains were cultivated in YEME as described by Hopwood et al. (1985). S. lividans 1326 containing the high-copy-number plasmid pIJ702 (Katz et al., 1983) was cultured as described by Hopwood et al. (1985).

The Escherichia coli plasmid pUC119 (Vieira \& Messing, 1987) was a gift from J. Vieira, Waksman Institute of Microbiology, Rutgers University. E. coli JM109 (Yanisch-Perron et al., 1985) competent cells and plating cultures for use as a host for pUC119 and M13 phages were purchased from Stratagene Cloning Systems.

DNA isolation and handling. E. coli and Streptomyces plasmids were isolated using alkaline lysis procedures. For $E$. coli this was a modification of the method of Birnboim \& Doly (1979) as described by Maniatis et al. (1982) and for Streptomyces the method of Kieser (1984) as described by Hopwood et al. (1985). Total DNA was isolated from all the Streptomyces strains using procedure 1 of Hopwood et al. (1985).

Southern hybridization and probe preparation. Southern blots of BamHI-digested total DNA were prepared as described by Maniatis $e t$ al. (1982). The $1.0 \mathrm{~kb}$ SalI fragment of IS 116 was sub-cloned into M13mp19, labelled with $\alpha-\left[{ }^{32} \mathrm{P}\right] \mathrm{dATP}$ using the M13 hybridization probe primer (Pharmacia) and used to probe the Southern blots. Prehybridization and hybridization were performed at $65^{\circ} \mathrm{C}$; the blots were then washed twice in $2 \times \mathrm{SSC}$ and twice in $0.2 \times \mathrm{SSC}$ solutions containing $0.1 \% \mathrm{SDS}$ for $30 \mathrm{~min}$ at $65^{\circ} \mathrm{C}$ (Maniatis et al., 1982).

Mapping of the insertion site in pIJ702, preparation of sub-clones and DNA sequence determination. The insertion of IS116 into pIJ702 was located by restriction mapping to a position between the ApaI site at $1320 \mathrm{bp}$ and the $B c /$ I site at position 2255 bp on the pIJ 702 circular map (Hopwood et al., 1985). One internal BclI fragment from IS 116 and two $B c l$ fragments containing IS 116 and pIJ702 flanking DNA, as well as the pIJ702 BclI fragments containing the unoccupied IS 116 insertion site, were sub-cloned into pUC119. The fragment containing the righthand end of IS116 DNA was further sub-cloned as smaller fragments into pUC119 and then all sub-clones in pUC119 were directionally cloned into the M13 vectors mpl8 and mp19 (Yanisch-Perron et al., 1985: Fig. 1). DNA was sequenced by the chain-termination procedure (Sanger et al., 1977) using the 'universal' primer and two specially synthesized oligonucleotide primers. The special primers permitted sequencing of two regions without the need to obtain small sub-clones. Both $\alpha-\left[{ }^{32} \mathrm{P}\right] \mathrm{dATP}$ (Amersham) and $\alpha-\left[{ }^{35} \mathrm{~S}\right] \mathrm{dATP}$ (New England Nuclear) were used as radioactive tracer in different experiments. Aberrations in the banding pattern were relieved by using 'sequenase' (United States Biochemicals) reactions with either dITP (Mills \& Kramer, 1979) or 7-deaza-dGTP (Mizusawa et al., 1986) in place of dGTP.

Analysis of sequences. The primary sequence data of IS116 were compiled using MacGene (Applied Genetic Technology, Inc.) and analysis of the nucleotide sequence for open reading frames (ORFs) was performed using FRAME (Bibb et al., 1984).

The FastP (Lipman \& Pearson, 1985) and Sweep programs were used

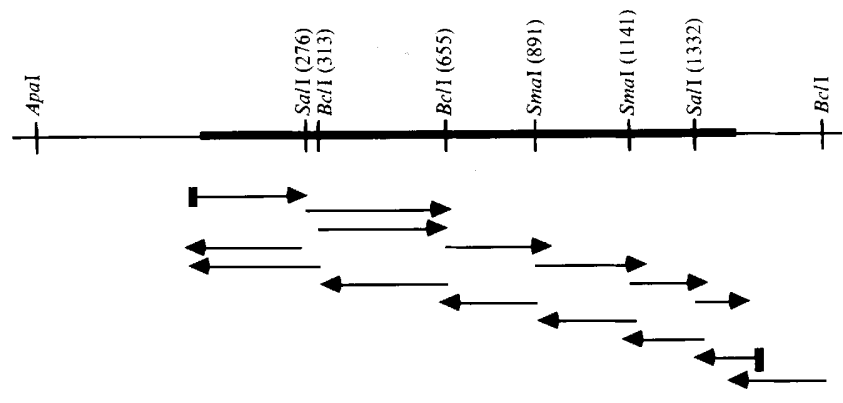

Fig. 1. Restriction map and strategy for DNA sequencing of IS 116 and flanking pIJ702 DNA. The thin line indicates pIJ702 DNA and the bold line indicates IS116 DNA. The numbers in parentheses refer to the base positions of the restriction sites, where 1 is the first base of IS 116 and 1421 is the last base. Vertical bars on arrows denote that a specially prepared synthetic oligonucleotide was used to obtain the sequence. Arrowheads show the length of sequence read from each sub-clone.

to screen the PIR protein sequence database (Release 10, W. C. Barker et al., National Biomedical Research Foundation, Georgetown University Medical Center, Washington, DC 20007, USA) and the Owl database (Version 1 1) for homology to the IS 116 ORF1197, IS 110 ORF1215 and the mini-circle ORF1. (The Sweep program is an extension of FastP, and the Owl database is a composite database compiled from several currently available protein and DNA sequence databases by A. J. Bleasby, University of Leeds, Leeds, UK).

The IS 116 ORF1197, ORF1215 of IS 110 , ORF 1197 of IS 900 and the mini-circle ORF1 sequences were aligned using the CLUSTAL programs (Higgins \& Sharp, 1988) for multiple sequence alignments. Pairwise comparisons of the putative polypeptide sequences were done using the COMPARE and DOTPLOT programs in the package supplied by the University of Wisconsin Genetics Computer Group, Version 5.3 (Devereux et al., 1984) with window and stringency parameters set at 40 and $19 \cdot 0$ respectively.

\section{Results}

\section{Isolation and distribution of IS116 and closely related sequences}

The insertion sequence IS 116 was first observed by chance after introduction of the Streptomyces plasmid pIJ702 (isolated from $S$. lividans 1326) into protoplasts prepared from NTG-mutagenized $S$. clavuligerus spores. Because of restriction of the foreign DNA, only three thiostrepton-resistant transformants were obtained, one of which was found to contain pIJ702 bearing a $1.4 \mathrm{~kb}$ insertion about $300 \mathrm{bp}$ anticlockwise of the $B c l \mathrm{I}$ site at position $2255 \mathrm{bp}$ on the pIJ702 circular map. The insertion was named IS 116 . A $1.0 \mathrm{~kb} S a l$ fragment from within IS116 (Fig. 1) was used to probe Southern blots of BamHI-digested total DNA from $S$. clavuligerus and nine other Streptomyces species using the stringency conditions described in Methods: S. lividans 1326, S. cattleya 


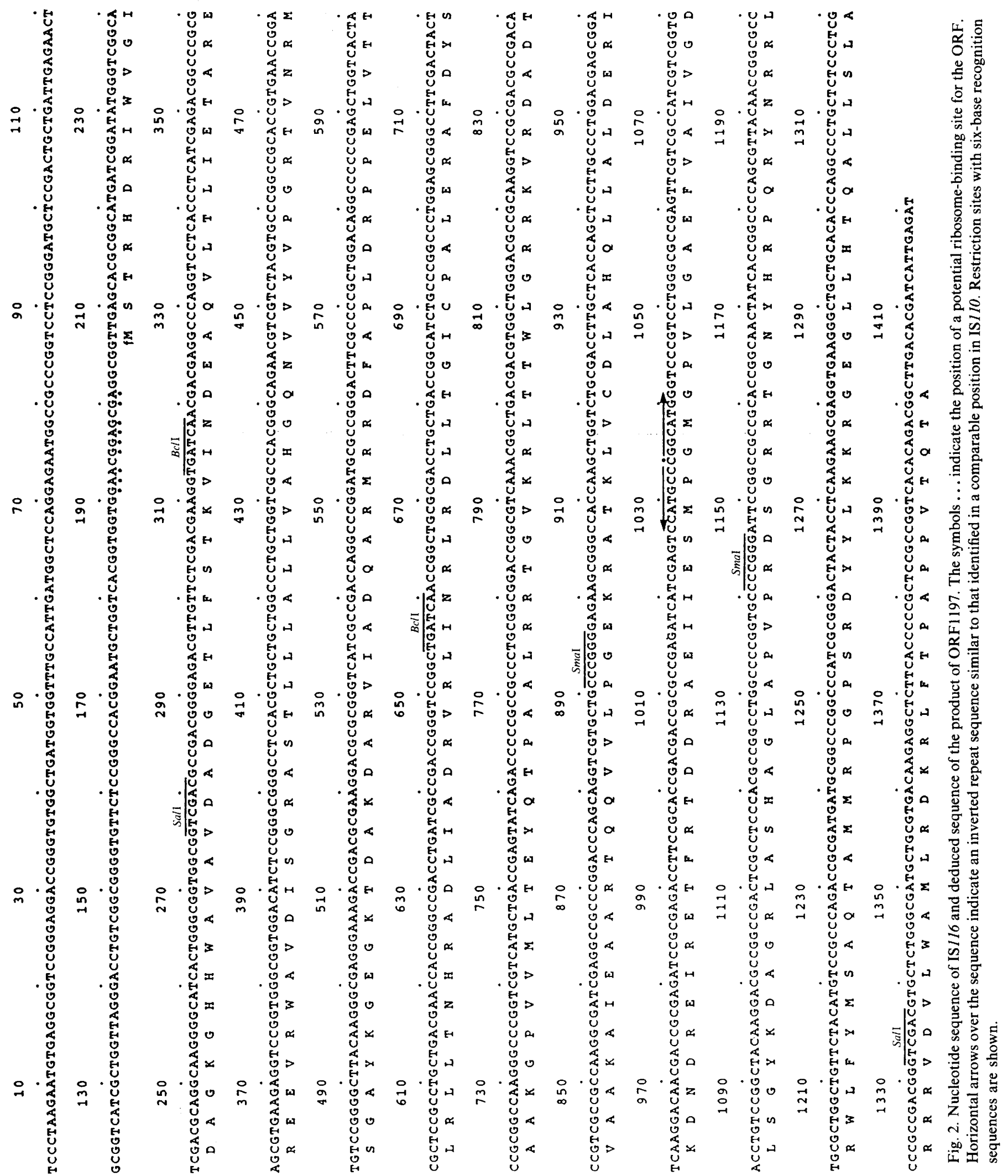


NR.RL 8057, $S$. fradiae NCIB 8233, $S$. griseus NCIB $8237, S$. lipmanii NRRL 3584, S. phaeochromogenes NCIB 8505 and $S$. rimosus NCIB 8229 showed little or no hybridization, but $S$. venezuelae NCIB 823 and $S$. violaceoruber SANK 95570 showed strong hybridization, with many bands being visible (data not shown). The probe hybridized to a single band of approximately $10 \mathrm{~kb}$ from $S$. clavuligerus, suggesting the presence of only one copy of IS 116 in the genome.

\section{IS116 contains one major gene, which is homologous to} genes in otherwise disparate actinomycete transposable elements

The nucleotide sequence of IS116 is shown in Fig. 2. The FRAME program was used to search the sequence for putative protein-coding ORFs. The plot identified a single ORF ending at a UGA triplet located only $15 \mathrm{bp}$ from the end of IS116. Consideration of the FRAME analysis and of the availability of potential ribosomebinding sites tended to exclude all the ATG or GTG triplets as likely translational start codons, but a TTG at position 207 is preceded by a good potential ribosomebinding site (Fig. 2). Moreover, a protein starting at this codon would show convincing end-to-end sequence alignment with the putative products of ORFs from other actinomycete mobile genetic elements (see below). This TTG codon was therefore chosen as the most likely start for the IS116 ORF, which would have a length of 1197 bp.

The putative protein product of ORF1197 showed no significant relatedness to any proteins in the major databases. However, pairwise comparisons to ORF1215 of the $S$. coelicolor IS 110 and to ORF1 of the $S$. coelicolor $2.6 \mathrm{~kb}$ mini-circle revealed a high degree of similarity between the protein products. The putative polypeptides from the two insertion sequences are more similar to each other than to the mini-circle ORF1 polypeptide, resembling each other throughout their length. An even closer relatedness was subsequently seen to the recently published (Green et al., 1989) sequence of the major ORF of IS 900 from Mycobacterium paratuberculosis. The most conserved regions of the four polypeptides are towards the ends, particularly the C-terminus. No extensive similarities between the DNA sequences of the four ORFs were revealed by DOTPLOT analysis.

In order to highlight any regions of the polypeptide sequences which, by virtue of their conservation, might represent structural or functional domains, they were aligned using the CLUSTAL programs for multiple sequence alignments (Fig. 3). Regions highly conserved among related proteins are potentially of functional significance, so short peptide sequences corresponding to these (Fig. 3) were used in a further search of the Leeds
University protein database (using the SCANDAL program developed by A. Bleasby, Department of Biophysics, University of Leeds: T. K. Attwood, personal communication). No significant relatedness to any proteins in the database was uncovered by this computer-assisted procedure, but examination of conserved regions by eye led to the recognition of some possible similarities to reverse transcriptase (see Discussion).

In view of the similarity of the major ORFs of IS 116 and IS 110 , we examined the sequence of IS 116 to see if two minor features of IS 110 noted by Bruton \& Chater (1987) were also present. A possible ORF of 330 nucleotides (ORF330) reading from the opposite strand of IS110 ORF1215 had a smaller counterpart (of 141 nucleotides) in IS 116 , and a conspicuous inverted repeat in ORF330 of IS110 was echoed by a somewhat shorter inverted repeat at the same position (nucleotide 1034) in IS116. Although an inverted repeat was not present at that location in the mini-circle ORF1 or IS 900 , potential ORFs (of 186 and a maximum length of 408 nucleotides, respectively) were found. However, as was the case for the ORF in IS116, these ORFs are preceded by weak ribosome-binding sites and the codon usage is not as expected for high-G + C DNA.

Features of the junctions of IS116 with its target site in pIJ702

IS 116 was inserted between bases 1922 and 1923 (Kendall \& Cohen, 1988) of pIJ101 (from which pIJ702 was derived), with no duplication of the target site (in contrast with the common situation with transposition of both prokaryotic and eukaryotic elements) (Fig. 4). Furthermore, the termini of IS 116 did not contain inverted repeat sequences, which usually characterize the ends of IS elements (Iida et al., 1983). Similarities of the IS116::pIJ702 junction sequences with those of several IS 900 insertions sequenced by Green et al. (1989) were noticed (see Discussion).

\section{Discussion}

\section{A family of transposable elements in actinomycetes}

A $1.4 \mathrm{~kb}$ insertion in pIJ702, isolated from $S$. clavuligerus and named IS 116 , is a previously undescribed insertion element that is probably present as a single copy in the chromosome of $S$. clavuligerus. The element is $1421 \mathrm{bp}$ long and contains an ORF which spans most of its length. Use of the most likely start codon (a TTG) would allow this ORF (ORF1197) to encode a protein product of $M_{\mathrm{R}} 44766$ ( 399 amino acids). This product is related to deduced gene products specified by IS 900 from 
Mini-circle

IS 110

IS 116

IS 900

Mini-circle

IS 110

IS 116

IS 900

Mini-circle

IS 110

IS 116

IS 900

HTLV-I

Mini-circle

IS 110

IS 116

IS 900

Mini-circle

IS 110

IS 116

IS 900

Mini-circle

IS 110

IS 116

IS 900

Mini-circle

IS 110

IS 116

IS 900

Mini-circle

IS 110

IS 116

IS 900

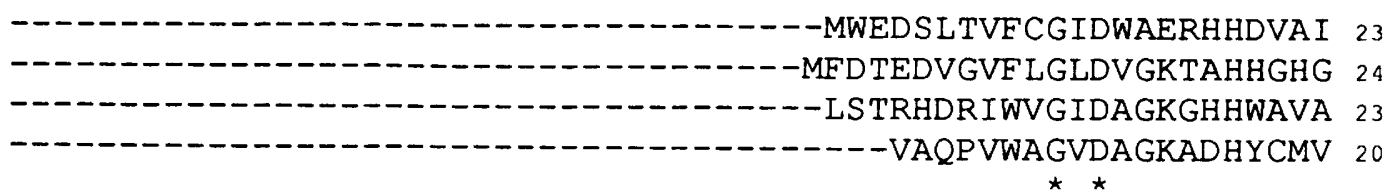

VDDTGTLLAKARITDDV----AGYNKLLDLLAEHGDSSATP IPVAIETSHGLLVAALRTG 79 LTPAGKKVLDKQLPNSEPRLRAVFDKLAAKFGT------VLVIVDQPAS IGALPLTVARD 78 VDADGETLFSTKVINDE----AQVLTLIE---TAREREEVRWAVDISGRASTLLLALIVA 76 INDDAQRLLSQRVANDE----AALLELIAAVTTLADGGEVTWAIDLNAGGAALLIALLIA 76

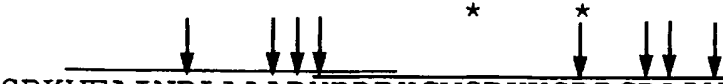

SRKVEA INP LAAARYRDRHGVSRKKSDPGDALVLAN ILRTDMHAHRP LPADSELAQAITV 139 AGCKVAY LPGLAMRRIADLYPGEAKTDAKDAAVIADAARTMAHTLRS LELTDEITAELSV 138 HGQNVVYVPGRTVNRMSGAYKGEGKTDAKDARVIADQAR-MRRDFAP LDRPPELVTTLRL 135 AGQRLLY IPGRTVHHAAGSYRGEGKTDAKDAAI IADQAR-MRHDLQP LRAGDDIAVELRI 135 ${ }_{56}$ YT GP GNNPVFPVKKANGTW $_{107} \mathrm{HLT}$ IDLRDAFFQIPL

. 0 ...... . . .......

LARAQQDAVWNRQQVANQVRSLLREYYPAALHAFQSKDGGLTRPDARVILTMAPTPAKAA 199 LVGFDQDLAAEATRT SNRIRGLLTQFHPSLERVLGPRLDHQ------ - - - - AVTW 183 LTNHRADLIADRVRL INRLRDLLTGICPALERAFDYSAAKG------------- PVVM 180 LTSRRSDLVADRTRA IEPNARPAAGILSALERAFDYNKSRA-- - - - - - - ALIL 180

KLTLAQLRAGLKRSGRTRAFNTE IERLRGIERSEYARQLPAVEDAF - - - GHQLLALLRQ 255 LLERYGSPAALRKAGRRRLVELVRPKAPRMAQRLIDDIFDALDEQTVVVPGTGTLDIVVP 243 -LTEYQTPAALRRTGVKRLTTWLGRRKVRDADTVAAKAIEAARTQQVVLPGEKRATKLVC 239 - LTGYQTPDALRSAGGARVAAFLRKRKARNADTVAATALQAANAQHS IVPGQQLAATVVA
$\star \star \star *$

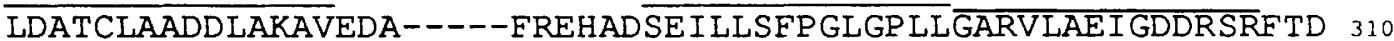
SLASSLTAVHEQRRALEAQINALLEAHP LSPVLTSMPGVGVRTAAVLL-VTVGDGTSFPT 302 DLAHQLLALDER IKDNDRE IRETERTDDRAE I IESMPGMGPVLGAEFV-A IVGDLSGYKD 298 RLAKEVMALDTE IGD TDAM IEERFRRHRHAE I I LSMPGFGVILGAEF LAATGGDMAAFAS 299 * $\quad$ *

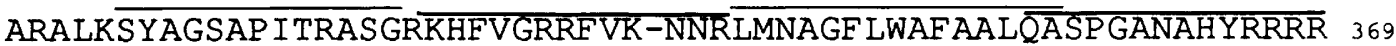
AAHLASYAGLAPTTKSSGTSIHGEHAP RGGNRQLKRAME LSAFACMNADPASRTYYDRQR 362 AGRLASHAGLAPVPRDSGRRTGNYHRPQRYNRRLRWLFYMSAQTAMMRPGP SRDYYLKKR 358 ADRLAGVAGLAPVPRDSGRISGNLKRPRRYDRRLLRACYLSALVSIRTDPSSRTYYDRKR 359

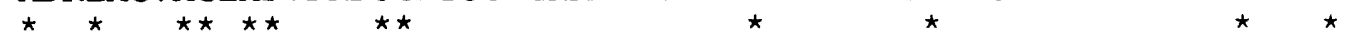

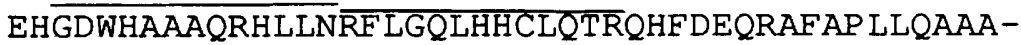
ARGKTHTQALLRLARQRISVLFAMLRDGTFYESRMPAGVELAA--GEGLLHTQALLSLARRRVDVLWAMLRDKRLET---PAPPVTQTA-TEGKRHTQAVLALARRRLNVLWAMLRDHAVYH-- -PA---TTTAAA

Fig. 3. Alignment of the IS116 ORF1197, IS900 ORF1197, IS 110 ORF1215 and the mini-circle ORF1 polypeptide sequences generated using CLUSTAL programs for multiple sequence alignments. The set parameters were as follows: gap penalty 4 , cut-off 10 , window 10 , and filtering 2.5. Pads added to maintain the alignment are indicated by $(-)$. Amino acid residue numbers are given at the ends of the lines. The short polypeptide sequences, derived from conserved regions, which were used to search databases are indicated by horizontal lines above the sequences. Symbols above and below the sequences denote the following: *, conserved residue among the four transposable elements; $\downarrow$, regions showing similarity to reverse transcriptase motifs; ., conserved residue type among reverse transcriptases; ${ }^{\circ}$, very highly conserved residue among reverse transcriptases; $\square$, shown to be significant by site-directed mutagenesis of HTLV-I. 
(a) Element-target site junctions

Mini-circle : : chromosome

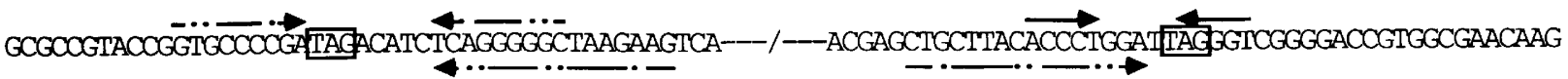

IS $110:: \phi C 31$

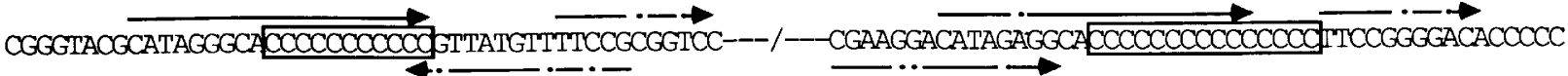

IS $116:$ :pIJ702

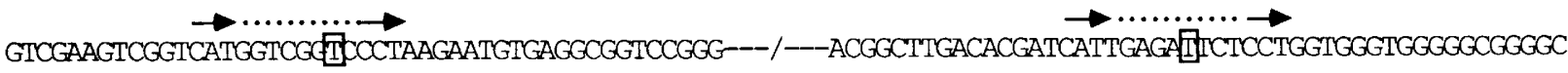

IS900 : : chromosome

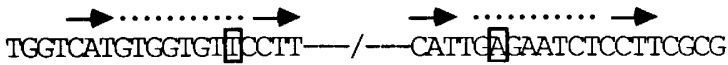

(b) Insertion sites

Mini-circle

GAGCGCCGTACCGGIGCCCCGATAGGGTCGGGGÄCCGIGGCGAACAAGAACATC

IS 110

CACCGGGTACGCATAGGGCACCCCCCCTTCCGGGGACACCCCCCTATCCGTCGAC

IS 116

$><$
TCCGICGAAGTCGGTCATGGTC̣GGTCTCCIGGIGGGTGGGGGCGGGCGCCACG

IS900

TGGICATGTGGTGTCTCCTTCGCG

Fig. 4. Target site junctions $(a)$ and insertion sites $(b)$ of the four actinomycete transposable elements (the insertion site shown for IS 900 was isolated in clone pMB22: Green et al., 1989). Direct and inverted repeats are indicated by arrows and the junction points are boxed. Symbols $><$ in $(b)$ show the limits within which the element-target site recombination is deduced to have occurred.

Mycobacterium paratuberculosis $(50 \%$ identity, three gaps in the alignment) and by IS 110 (ORF1215;35\% identity with six gaps) and the mini-circle (ORF $1 ; 25 \%$ identity with nine gaps), both from $S$. coelicolor A3(2). The latter two polypeptides show $22 \%$ identity (seven gaps). Thus the mini-circle ORF1 appears to be more divergent than the other three. Since ORF1 of the mini-circle is essential for integration of the circular form of the element into the S. lividans chromosome (D. J. Henderson, unpublished), it probably encodes an integrase or transposase. The resemblance of this protein to those specified by IS 110 , IS 116 and IS 900 suggests that they have a comparable function.

Similarities and differences between the ends and target sites of members of the family of elements

The similarities of their major gene products lead one to anticipate that IS110, IS 116 , IS 900 and the mini-circle should show similar features at their ends. In fact, 
however, IS 110 and the mini-circle possess imperfect inverted repeats at their ends, but IS 116 and IS 900 do not (with the caveat that only one example of IS 116 has been sequenced; however, the possibility that it might have suffered deletion of some terminal sequences seems unlikely since the sequences flanking the element are not deleted). Unusually, the insertion of IS 116 , IS900 or the mini-circle does not cause target site duplications (Fig. 4; Green et al., 1989; Henderson et al., 1989) [the situation for IS110 is unclear because in the particular insertion event that was sequenced by Bruton \& Chater (1987) the element had inserted into a run of seven $C$ residues and was then flanked by runs of more than seven $C$ residues]. The site into which IS116 is inserted in pIJ702 (CATGGTCGGTCTCCTGGT) corresponds closely to the consensus sequence $\mathrm{CATG}(\mathrm{N})_{4-6} \mathrm{CPyCCTT}$ proposed as the target site for IS 900 insertion, based on analysis of three insertion events (Fig. 4; Green et al., 1989). Moreover, the leftmost 6 and rightmost 17 residues of IS900 (Green et al., 1989) are closely similar to the corresponding segments of IS 116 .

IS116 shows little homology to its target site in pIJ702, with the caveat mentioned above, although the sequences CAT, repeated a few bases to the left of both junctions of the inserted element, and CCT, a few bases to the right of these junctions, merit emphasis because they are also found in all three of the IS900 insertion events in Mycobacterium analysed by Green et al. (1989). These short sequences might conceivably guide the alignment of a circular transposition intermediate and its target site as has been proposed for short regions of similarity between both the mini-circle and IS 110 and their respective target sites (Henderson et al., 1989; Bruton \& Chater, 1987). Such alignments between short related sequences have been strongly implicated in integration of $\mathrm{Tn} 7$ in E. coli (Gringauz et al., 1988) and Tn554 in Staphylococcus aureus (Murphy, 1988).

\section{$A$ weak similarity between proteins specified by the elements and reverse transcriptases}

Database searches failed to reveal other proteins containing sequences similar to the regions most highly conserved between the putative transposases (integrases) of IS116, IS 110 , IS 900 and the mini-circle. Nevertheless, it is interesting to note that one of the most highly conserved segments (corresponding to IS 116 residues 103-107: Fig. 3) contains an invariant motif D--DA that is also conserved in retroviral reverse transcriptases (Patarca \& Haseltine, 1984; Johnson et al., 1986; Xiong $\&$ Eickbush, 1988) and which has been shown there, by site-directed mutagenesis, to be functionally significant (Fig. 3; Larder et al., 1987). On the other hand, the actinomycete sequences lack two other sequence motifs that are very highly conserved among retroviral reverse transcriptases: LPQG and Y-DD, the latter being conserved also among other nucleic acid polymerases (Johnson et al., 1986; Argos, 1988). However it is worth noting that a region upstream of the D--DA motif (starting in IS 116 at $\mathrm{P}_{85}$ ) shows some degree of similarity to a second moderately well conserved region in the retroviral enzymes (Johnson et al., 1986; Xiong \& Eickbush, 1988) (Fig. 3). Comparison with the recently discovered reverse transcriptases of Gram-negative bacteria reinforces these tentative alignments (Lampson et al., 1989; Inouye et al., 1989; Lim \& Maas, 1989). Thus, although these sequence comparisons do not imply that some or all of these actinomycete elements use reverse transcription during their transposition, it seems plausible that their principal gene products may have some properties in common with reverse transcriptases. In addition, reverse transcriptases are a very highly diverged but undoubtedly homologous family of enzymes and no other transposition-related enzyme family is encoded by, and crucial to, such a wide variety of transposing elements. These two features are also shown by the gene products of the actinomycete elements discussed here.

We thank Teresa Attwood and John Wooton of the University of Leeds for assistance with database searches. This work was supported by grants from the Natural Sciences and Engineering Research Council of Canada (B.K.L., S. E. J.), Alberta Heritage Foundation for Medical Research (B.K.L., S.E.J., M.M.) and the John Innes Foundation (D.J.H.).

\section{References}

ARGos, P. (1988). A sequence motif in many polymerases. Nucleic Acids Research 16, 9909-9916.

BAILEY, C. R. \& WINSTANLEY, D. J. (1986). Inhibition of restriction in Streptomyces clavuligerus by heat treatment. Journal of General Microbiology 132, 2945-2947.

BibB, M. J., FindLAY, P. R. \& Johnson, M. W. (1984). The relationship between base composition and codon usage in bacterial genes and its use in the simple and reliable identification of protein coding sequences. Gene $30,157-166$.

Birnboim, H. C. \& Doly, J. (1979). A rapid alkaline extraction procedure for screening recombinant plasmid DNA. Nucleic Acids Research 7, 1513-1523.

Bruton, C. J. \& Chater, K. F. (1987). Nucleotide sequence of IS110, an insertion sequence of Streptomyces coelicolor A3(2). Nucleic Acids Research 15, 7053-7065.

Chater, K. F., Bruton, C. J., Foster, S. G. \& Tobek, I. (1985). Physical and genetic analysis of IS 110 , a transposable element of Streptomyces coelicolor A3(2). Molecular and General Genetics 200, 235-239.

Chater, K. F., Henderson, D. J., Bibb, M. J. \& Hopwood, D. A. (1988). Genome flux in Streptomyces coelicolor and other streptomyces and its possible relevance to the evolution of mobile antibiotic resistance determinants. In Transposition, pp. 7-42. Edited by A. J. Kingsman, K. F. Chater \& S. M. Kingsman. Cambridge: Cambridge University Press.

DevereuX, J., Haeberli, P. \& Smithies, O. (1984). A comprehensive set of sequence analysis programs for the Vax. Nucleic Acids Research 12, 387-395. 
Green, E. P., Tizard, M. L. V., Moss, M. T., Thompson, J., WINTERBourNe, D. J., MCFADDEN, J. J. \& HERMON-TAYLOR, J. (1989). Sequence and characteristics of IS 900 , an insertion element identified in a human Crohn's disease isolate of Mycobacterium paratuberculosis. Nucleic Acids Research 17, 9063-9073.

Gringauz, E., Orle, K. A., Waddell, C. S. \& Craig, N. L. (1988). Recognition of Escherichia coli att $\mathrm{Tn} 7$ by transposon $\mathrm{Tn} 7$ : lack of specific sequence requirements at the point of $\operatorname{Tn} 7$ insertion. Journal of Bacteriology 170, 2832-2840.

Henderson, D. J., Lydiate, D. J. \& Hopwood, D. A. (1989). Structural and functional analysis of the mini-circle, a transposable element of Streptomyces coelicolor A3(2). Molecular Microbiology 3, 1307-1318.

Higgins, D. G. \& Sharp, P. M. (1988). Clustal: a package for performing multiple sequence alignment on a microcomputer. Gene 73, 237-244.

HÜTTER, R. \& ECKHARDT, T. (1988). Genetic manipulation. In Actinomycetes in Biotechnology, pp. 89-184. Edited by M. Goodfellow, S. T. Williams \& M. Mordarski. London: Academic Press.

Hopwood, D. A., Bibb, M. J., Chater, K. F., Kieser, T., Bruton, C. J., Kieser, H. M., Lydiate, D. J., SMith, C. P., Ward, J. M. \& SCHREMPF, H. (1985). Genetic Manipulation of Streptomyces - a Laboratory Manual. Norwich: John Innes Foundation.

IIDA, S., MEYeR, J. \& ARBER, W. (1983). Prokaryotic IS elements. In Mobile Genetic Elements, pp. 159-221. Edited by J. A. Shapiro. New York: Academic Press.

InOUYe, S., Hsu, M.-Y., Eagle, S. \& INOUYe, M. (1989). Reverse transcriptase associated with the biosynthesis of the branched RNAlinked msDNA in Myxococcus xanthus. Cell 56, 709-717.

Jensen, S. E., Westlake, D. W. S. \& Wolfe, S. (1982). Cyclization of $\delta$-(L- $\alpha$-aminoadipyl)-L-cysteinyl-D-valine to penicillins by cell free extracts of Streptomyces clavuligerus. Journal of Antibiotics 35, 483490.

Jensen, S. E., Leskiw, B. K., Vining, L. C., Aharonowitz, Y., Westlake, D. W. S. \& Wolfe, S. (1986). Purification of isopenicillin N synthetase from Streptomyces clavuligerus. Canadian Journal of Microbiology 32, 953-958.

Johnson, M. S., McClure, M. A., Feng, D.-F., Gray, J. \& DoolitTle, R. F. (1986). Computer analysis of retroviral pol genes: assignment of enzymatic function to specific sequences and homologies with non-viral enzymes. Proceedings of the National Academy of Sciences of the United States of America 83, 7648-7652.

KatZ, E., Thompson, C. J. \& Hopwood, D. A. (1983). Cloning and expression of the tyrosinase gene from Streptomyces antibioticus in Streptomyces lividans. Journal of General Microbiology 129, 27032714.

KENDALl, K. J. \& COHEN, S. N. (1988). Complete nucleotide sequence of the Streptomyces lividans plasmid $\mathrm{pIJ} 101$ and correlation of the sequence with genetic properties. Journal of Bacteriology 170, 46344651.

KIESER, T. (1984). Factors affecting the isolation of CCC DNA from Streptomyces lividans and Escherichia coli. Plasmid 12, 19-36.
Lampson, B. C., Sun, J., Hsu, M.-Y., Vallejo-Ramirez, J., Inouye, S. \& INOUYE, M. (1989). Reverse transcriptase in a clinical strain of Escherichia coli: production of branched RNA-linked msDNA. Science 243, 1033-1038.

Larder, B. A., Purifoy, D. J. M., Powell, K. L. \& Darby, G. (1987). Site-specific mutagenesis of AIDS virus reverse transcriptase. Nature, London 327, 716-712.

Leskiw, B. K., Aharonowitz, Y., Mevarech, M., Wolfe, S., Vining, L. C., Westlake, D. W. S. \& Jensen, S. E. (1988). Cloning and nucleotide sequence determination of the isopenicillin $\mathrm{N}$ synthetase gene from Streptomyces clavuligerus. Gene 62, 187-196.

LiM, D. \& MAAS, W. K. (1989). Reverse transcriptase-dependent synthesis of a covalently linked branched DNA-RNA compound in Escherichia coli B. Cell 56, 891-904.

Lipman, D. J. \& Pearson, W. R. (1985). Rapid and sensitive protein similarity searches. Science 227, 1435-1441.

Lydiate, D. J., IkeDA, H. \& HopwoOd, D. A. (1986). A $2.6 \mathrm{~kb}$ DNA sequence of Streptomyces coelicolor A3(2) which functions as a transposable element. Molecular and General Genetics 203, 79-88.

Lydiate, D. J., Ashby, A. M., Henderson, D. J., Kieser, H. M. \& HoPWOOD, D. A. (1989). Physical and genetic characterization of linear copies of the Streptomyces coelicolor mini-circle. Journal of General Microbiology 135, 941-955.

Maniatis, T., Fritsch, E. F. \& SAMBrooK, J. (1982). Molecular Cloning - a Laboratory Manual. Cold Spring Harbor, NY: Cold Spring Harbor Laboratory.

Mills, D. R. \& KRAmer, F. R. (1979). Structure-independent nucleotide sequence analysis. Proceedings of the National Academy of Sciences of the United States of America 76, 2232-2235.

Mizusawa, S., Nishimura, S. \& Seela, F. (1986). Improvement of the dideoxy chain termination method of DNA sequencing by use of deoxy-7-deazaguanosine triphosphate in place of dGTP. Nucleic Acids Research 14, 1319-1324.

MURPHY, E. (1988). Transposable elements in Staphylococcus. In Transposition, pp. 59-89. Edited by A. J. Kingsman, K. F. Chater \& S. M. Kingsman. Cambridge: Cambridge University Press.

O'Sullivan, J., Aplin, R. T., Stevens, C. M. \& Abraham, E. P. (1979). Biosynthesis of a 7- $\alpha$-methoxycephalosporin. Biochemical Journal 179, 47-52.

Patarca, R. \& Hasteltine, W. A. (1984). Sequence similarity among retroviruses - erratum. Nature, London 309, 728.

SANGer, F., Nicklen, S. \& Coulson, A. R. (1977). DNA sequencing with chain-terminating inhibitors. Proceedings of the National Academy of Sciences of the United States of America 74, 5463-5467.

VieIRA, J. \& MESSING, J. (1987). Production of single-stranded plasmid DNA. Methods in Enzymology 153, 3-11.

Xiong, Y. \& EICKBUSH, T. H. (1988). Similarity of reverse transcriptase-like sequences of viruses, transposable elements, and mitochondrial introns. Molecular Biology of Evolution 5, 675-690.

Yanisch-Perron, C., Vieira, J. \& Messing, J. (1985). Improved M13 phage cloning vectors and host strains: nucleotide sequences of the M13mp18 and pUC19 vectors. Gene 33, 103-119. 